\title{
Cone Beam Computed Tomography and Digital Periapical Radiography in Determining Horizontal Root Fractures: An In-vitro Comparative Study
}

\section{Seyed Mohsen Hashemnia ${ }^{1}$, Sanaz Jahadi ${ }^{2}$, Shiva Shaygannia ${ }^{3}$, Ehsan Hekmatian ${ }^{4}$, Amirhosein Habibollahi ${ }^{*}$, Maryam Ghazizadeh ${ }^{5}$}

${ }^{1}$ Dental Material Research Center, Department of Endodontics, School of Dentistry, Isfahan University of Medical Sciences, Isfahan, Iran

${ }^{2}$ Department of Endodontics, School of Dentistry, Isfahan University of Medical Sciences, Isfahan, Iran

${ }^{3}$ Dental Student, Dental Student Research Committee, School of Dentistry, Isfahan University of Medical Sciences, Isfahan, Iran

${ }^{4}$ Committee of Radiology Research Torabinejad Dental Research Center, Department of Radiology, School of Dentistry, Isfahan University of Medical Sciences, Isfahan, Iran

${ }^{5}$ Post Graduate student of Oral and Maxillofacial Radiology, Dental Students Research Committee, School of Dentistry, Isfahan University of Medical Sciences, Isfahan, Iran

"Corresponding author: Amirhosein Habibollahi, Post Graduate student of Oral and maxillofacial radiology, Dental Students Research Committee, School of Dentistry, Isfahan University of Medical Sciences, Isfahan, Iran, Tel: 09366568896; E-mail: farrokhhabib@yahoo.com

Received date: August 13, 2018; Accepted date: September 12, 2018; Published date: September 18, 2018

Copyright: (c) 2018 Hashemnia SM, et al. This is an open-access article distributed under the terms of the Creative Commons Attribution License, which permits unrestricted use, distribution, and reproduction in any medium, provided the original author and source are credited.

\begin{abstract}
Background and objective: Diagnosis of Horizontal Root Fractures (HRF) is based on clinical and radiographic documents. The aim of this study was to compare the diagnostic accuracy of digital Periapical Radiographs (PSP) with different angulations in different locations and Cone Beam Computed Tomography (CBCT) in the detection of HRF in central and lateral maxillary incisors.

Materials and Methods: For this experimental study, 60 human central and lateral maxillary incisors were selected and were divided into 4 groups and were numbered. Root fractures were created by using mechanical force in the apical third, middle and cervical part of roots in the groups 1 to 3 . The last group was considered as a control group without any fractures. The two fragments from each tooth were relocated with super glue. Then, the radiographic images of all the teeth were taken using digital PSP and CBCT methods. Afterward, two oral and maxillofacial radiologists assessed the images separately. The data were subjected to specificity and sensitivity for each radiographic technique. The kappa statistics were used for assessing the agreement between observers. The Significance level was considered as $\mathrm{P}<0 / 05$.
\end{abstract}

Results: CBCT method had higher specificity and sensitivity in the detection of HRF compared to PSP. Kappa value for inter-observer agreement in HRF was 0/89 for CBCT and 0/725 for PSP.

Conclusion: CBCT outperformed the PSP method in detecting simulated HRF. CBCT should be used as the reliable imaging method for the diagnosis of HRF.

Keywords: Cone-beam computed tomography; Dental; Digital; Radiography; Tooth fractures

\section{Introduction}

Dental trauma is fairly common in permanent dentition in children and adults and may commonly result in tooth and/or alveolar fracture [1].

Root fracture is one of the most common causes of inadequate endodontic treatment. These fractures are more common in males (because of sports accidents, fights, etc...) and in anterior maxillary teeth particularly when full erupted and fully root formed teeth [2-5].

Horizontal Root Fracture (HRF) a type of fracture that is more common in the central incisor teeth $(68 \%)$ of maxilla (27\%), and is often seen in the form of a loosened tooth that is inclined toward the palate [6].

HRF has reported in up to 7 percent in dental trauma cases [7]. And its prevalence is $0.5 \%$ to $7 \%$ of dental trauma [8]. Dental root fractures have identified since two-dimensional radiography was used in dentistry in $1896[9,10]$. Recently we apply digital periapical radiography and $\mathrm{CBCT}$ to detect root fractures as a digital intraoral radiography method [11]. Periapical radiography (PR) is an important diagnostic tool for general practitioners and dental specialists. However, this method shows a two-dimensional image, that does not have the ability to view the buccal and lingual (or palatine) regions and resulting in superimposition of structures [12].

$\mathrm{CBCT}$ is an imaging technique that allows a three-dimensional analysis of teeth and bone structure in the oral cavity and was introduced in dento-alveolar imaging in 1998 [13]. This method allows the dentist to give a more accurate interpretation of dental and alveolar lesions and analyze the area through reconstructed multi-plan images. (Axial, coronal and sagittal planes) [14].

Detection of HRFs is generally based on clinical symptoms and intraoral radiography $[15,16]$. Fracture line is often oblique in a buccolingual direction [7], so it needs several intraoral periapical Images in different projections [17]. 
Citation: Hashemnia SM, Jahadi S, Shaygannia S, Hekmatian E, Habibollahi A, et al. (2018) Cone Beam Computed Tomography and Digital Periapical Radiography in Determining Horizontal Root Fractures: An In-vitro Comparative Study. Dentistry 8: 513. doi: 10.4172/2161-1122.1000513

Page 2 of 6

Prognosis of fractured teeth depends on several factors like the stage of development (open or close apex), a degree of displacement of a coronal part, loosening of coronal part and width of diastema between two parts of fracture $[7,18]$.

In literature, 3 different angles $\left(45^{\circ}, 90^{\circ}\right.$ and $\left.110^{\circ}\right)$ to tooth long axis have been reported for detection of fractures in initial periapical radiographic examinations [17].

The goal of treatment in such cases is to maintain the vitality of pulp and prevention of pulp necrosis. Pulp necrosis occurs in 25 percent of all cases so the rapid diagnosis of the fractures is important $[6,13,15,19]$.

Interpretation of root fracture has difficulties in radiographs especially when there is no displacement of fracture parts that is due to edema or granulation tissue formation around the fracture area so it is important to use the imaging technique which has the best diagnostic accuracy $[20,21]$.

Recently different other imaging techniques have been used for overcoming the limitations of intraoral images such as magnification, distortion and anatomic superimpositions. It seems that CBCT has none of these limitations, so it is preferred $[22,23]$. So, CBCT is used as a valuable imaging method in various dentistry fields such as surgery and orthodontics [18].

Although СВCT has many advantages in comparison with digital intraoral radiography, in most dental clinics the first available radiography is periapical radiographs. So we chose these two techniques for the detection of HRFs [14].

The aim of this study was to compare the diagnostic accuracy of СBCT and digital periapical radiographs in detection of in-vitro HRFs.

\section{Material and Methods}

In this in-vitro cross sectional study a total of 60 healthy maxillary central and lateral teeth without any pathologic lesions, root fractures or caries were collected from dental clinics in Isfahan, Iran in June 2016.

We divided 60 teeth into 4 groups of 15 numbered. Horizontal fractures were made in the upper third, the middle third and the apical third using the mechanical force of the hammer in the direction of the horizontal axis of the tooth in three groups and then fractured parts connected using the adhesive acrylate. The 15 teeth of the fourth group also had no fracture as control group.

Any pathologic lesions, root fractures, caries in the root were our exclusion criteria.

The teeth were randomly placed in a dried skull in the central and lateral maxillary area. In order to reconstruct the maxillary soft tissue we used two layers of thermoplastic wax for simulation. Then digital periapical images were obtained at 3 angles $45^{\circ}, 90^{\circ}$, and $110^{\circ}$ followed by CBCT imaging. After imaging, two radiologists viewed the images. Observers were aware that some of teeth had no fractures so the radiolucent line was defined in the images as a fracture line.

The viewers had unrestricted time and were allowed to enlarge the images, adjust the contrast and to zoom in and out. All digital periapical images were provided with exposure parameters: $63 \mathrm{kvp}, 7$ $\mathrm{mA}$ in $0 / 2$ seconds taken with the Vista Scan phosphor plate system (Dürr Dental, Beitigheim-Bissingen, Germany), size 2 (active area $30 \times$
$40 \mathrm{~mm}$ ) and processed in Scanora 5.0 (Sordex, Helsinki, Finland) software.

Then the images were viewed in 22 inches medical monitor (LG, Seoul, Korea) $(6900 \times 1440$ pixels, 32 bits $)$ in a dimly lit room by two observers (an oromaxillofacial radiologist and an endodontist) separately, randomly and the observers were blind to presence of fracture in observed teeth.

The CBCT images were provided by the Gallileos comfort 3D imaging unit (sirona Dental system Inc., Bensheim, Germany) with exposure conditions of $85 \mathrm{kvp}, 28 \mathrm{mAs}$ and a resolution of $100 \mu \mathrm{m}$ and images analyzed by GALAXIS viewer version 1.944(ID2)(SICAT gmbh and Co.KG).

All provided images were viewed two times with 1 month interval and horizontal root defects categorized in three groups: fracture confirmed uncertainty, and failure to see. Sensitivity and specificity of each of the radiographic methods were evaluated and reported using the SPSS software. The kappa statistic was used to express the agreement between viewers and Significance level $(\mathrm{P}<0.05)$ was considered.

\section{Results}

This study was confirmed to Determination and comparing the accuracy of CBCT imaging with PA in horizontal root fractures and Comparison of PA imaging accuracy in determining horizontal root fractures at three different angles and three different regions. $(45,90$, and 110) (Apical, cervical and middle)

Table 1 and ROC curve show the results for sensitivity and specificity for both CBCT images and periapical radiographs for root fractures.

\begin{tabular}{|c|c|c|c|c|c|}
\hline \multirow{2}{*}{$\begin{array}{l}\text { System } \\
\text { CBCT }\end{array}$} & \multicolumn{2}{|c|}{ Observer Evaluation } & \multirow{2}{*}{$\begin{array}{l}\text { Sensitivity } \\
0 / 97\end{array}$} & \multirow{2}{*}{$\begin{array}{l}\text { Specificity } \\
1\end{array}$} & \multirow{2}{*}{$\begin{array}{l}\text { Kappa } \\
0 / 87\end{array}$} \\
\hline & First & First & & & \\
\hline & & Second & $0 / 97$ & 1 & $0 / 87$ \\
\hline & & Mean & $0 / 97$ & 1 & $0 / 87$ \\
\hline \multirow[t]{3}{*}{ PA } & First & First & $0 / 87$ & $0 / 84$ & $0 / 75$ \\
\hline & & Second & $0 / 83$ & 1 & $0 / 75$ \\
\hline & & Mean & $0 / 85$ & $0 / 92$ & $0 / 75$ \\
\hline \multirow[t]{3}{*}{ СВСТ } & Second & First & $0 / 98$ & $0 / 87$ & $0 / 91$ \\
\hline & & Second & $0 / 97$ & $0 / 87$ & $0 / 91$ \\
\hline & & Mean & $0 / 975$ & $0 / 87$ & $0 / 91$ \\
\hline \multirow[t]{3}{*}{ PA } & Second & First & $0 / 81$ & $0 / 76$ & $0 / 70$ \\
\hline & & Second & $0 / 83$ & $0 / 87$ & $0 / 70$ \\
\hline & & Mean & $0 / 82$ & $0 / 815$ & $0 / 70$ \\
\hline
\end{tabular}

Table 1: Diagnostic results of horizontal root fracture evaluation based on radiographic method.

According to ROC curve (Figure 1) and the findings from statistical data in Table 1, the sensitivity ranging for CBCT imaging was 0/97 to $0 / 975$ and for PA imaging was $0 / 82$ to $0 / 85$ and the specificity ranging 
Citation: Hashemnia SM, Jahadi S, Shaygannia S, Hekmatian E, Habibollahi A, et al. (2018) Cone Beam Computed Tomography and Digital Periapical Radiography in Determining Horizontal Root Fractures: An In-vitro Comparative Study. Dentistry 8: 513. doi: 10.4172/2161-1122.1000513

Page 3 of 6

for CBCT imaging was $0 / 87$ to 1 and for PA radiographs was $0 / 815$ to $0 / 92$.

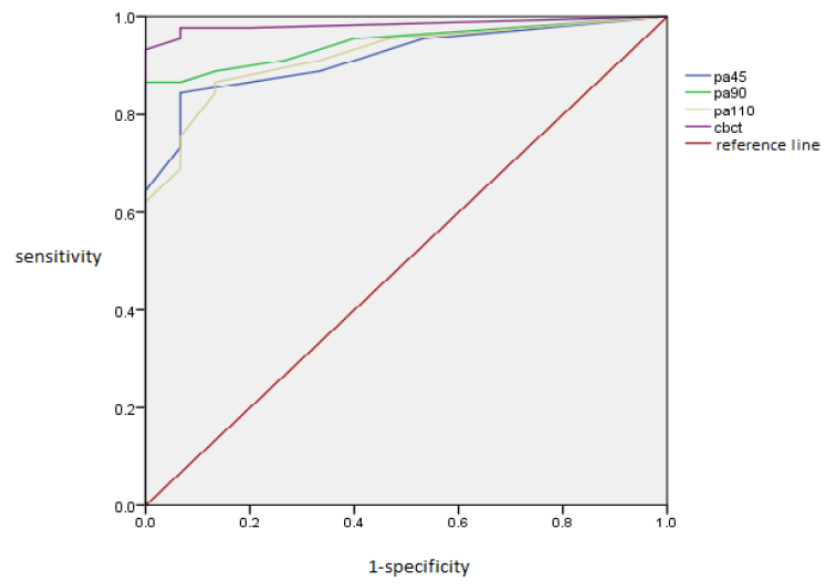

Figure 1: ROC curve for specificity and sensitivity of CBCT and digital periapical radiographs.

So the CBCT technique has a higher sensitivity and specificity than the periapical method in the diagnosis of HRFs. The Kappa coefficient for the $\mathrm{CBCT}$ technique is 0.89 and for the periapical technique is $0.725(\mathrm{P}<0.001)$.

Table 2 compares the accuracy of PA radiographs and CBCT images.

\begin{tabular}{|c|c|}
\hline Imaging technique & Accuracy \\
\hline PA 45 & $0 / 918$ \\
\hline PA90 & $0 / 947$ \\
\hline PA110 & $0 / 921$ \\
\hline CBCT & $0 / 984$ \\
\hline
\end{tabular}

Table 2: Comparison of the accuracy of imaging techniques (area under the ROC curve).

It can be seen from the data in Table 2, CBCT and periapical images with angles $90^{\circ}, 110^{\circ}$ and $45^{\circ}$ respectively had the highest accuracy in the diagnosis of horizontal root fracture. Table 3 presents Comparison of sensitivity for 3 different angles of periapical radiographs in regions of the root.

\begin{tabular}{|l|l|l|l|}
\hline Root region & $45^{\circ}$ & $90^{\circ}$ & $110^{\circ}$ \\
\hline Apical third & $0 / 66$ & $0 / 71$ & $0 / 63$ \\
\hline Middle third & $0 / 94$ & $0 / 91$ & $0 / 88$ \\
\hline Coronal third & $0 / 93$ & $0 / 94$ & $0 / 85$ \\
\hline
\end{tabular}

Table 3: Comparison of sensitivity for 3 different angles of periapical radiographs in regions of the root.

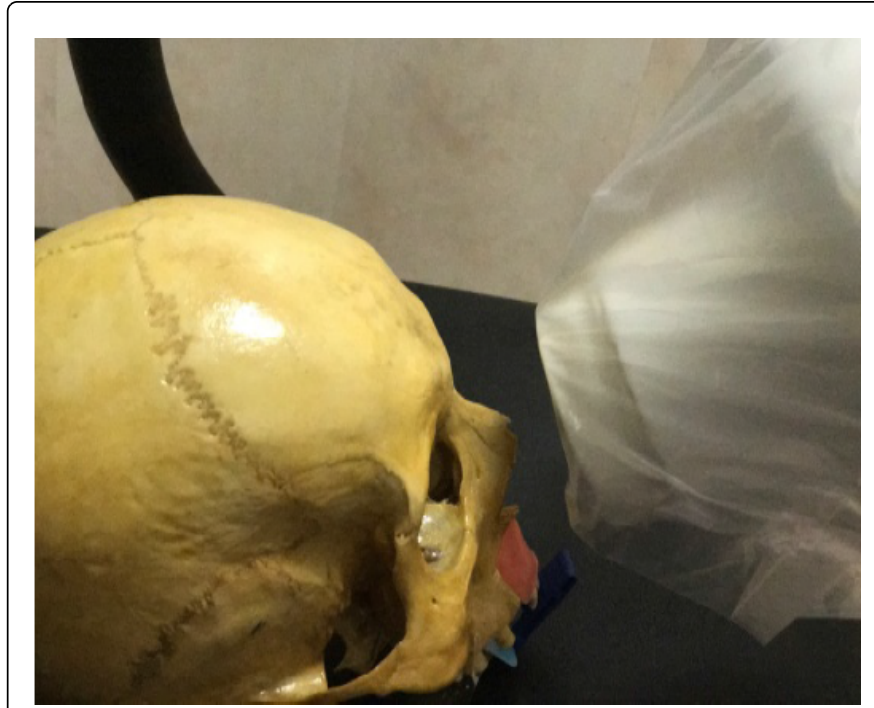

Figure 2: Tube positioning for periapical image at $90^{\circ}$.

Based on the findings of Table 3 between intra-oral radiographs, apical third and upper third (cervical), images with $90^{\circ}$ angle had the highest sensitivity among the other angles. Also, the images at $45^{\circ}$ had the highest sensitivity to detect the horizontal root fracture of the middle region (Figures 2 and 3).

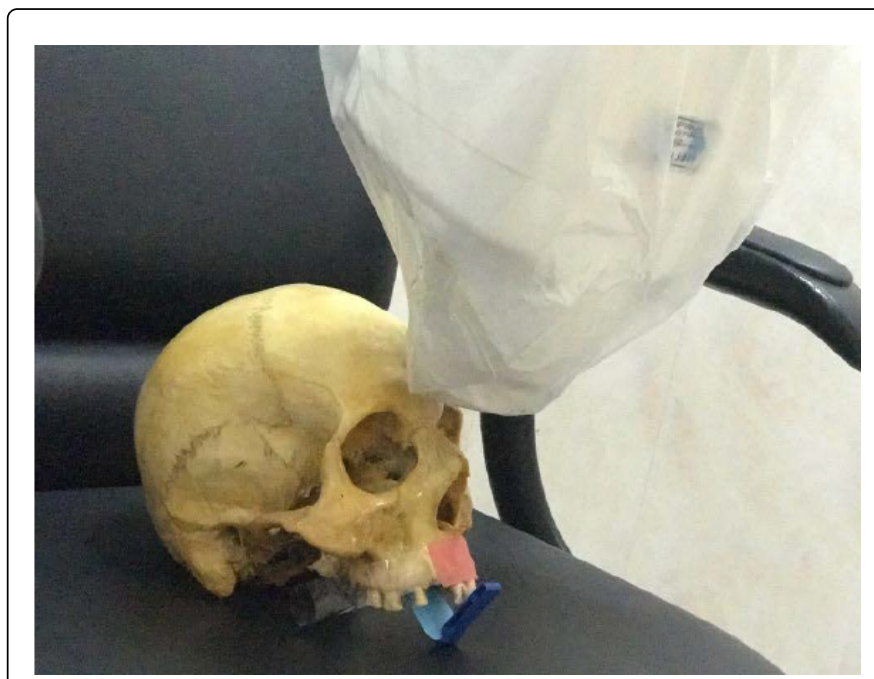

Figure 3: Tube positioning for periapical image at $110^{\circ}$.

\section{Discussion}

HRF and VRF have always been difficult to diagnose intraoral radiographs. The correct and on-time diagnosis of this type of fracture will improve the treatment process and prevents tooth and bone loss [24].

In this in vitro comparative study we aimed to assess the diagnostic accuracy (sensitivity and specificity) of Cone Beam Computed Tomography and Digital Periapical Radiography in Horizontal root fractures (Figure 4). 
Citation: Hashemnia SM, Jahadi S, Shaygannia S, Hekmatian E, Habibollahi A, et al. (2018) Cone Beam Computed Tomography and Digital Periapical Radiography in Determining Horizontal Root Fractures: An In-vitro Comparative Study. Dentistry 8: 513. doi: $10.4172 / 2161-1122.1000513$

Page 4 of 6

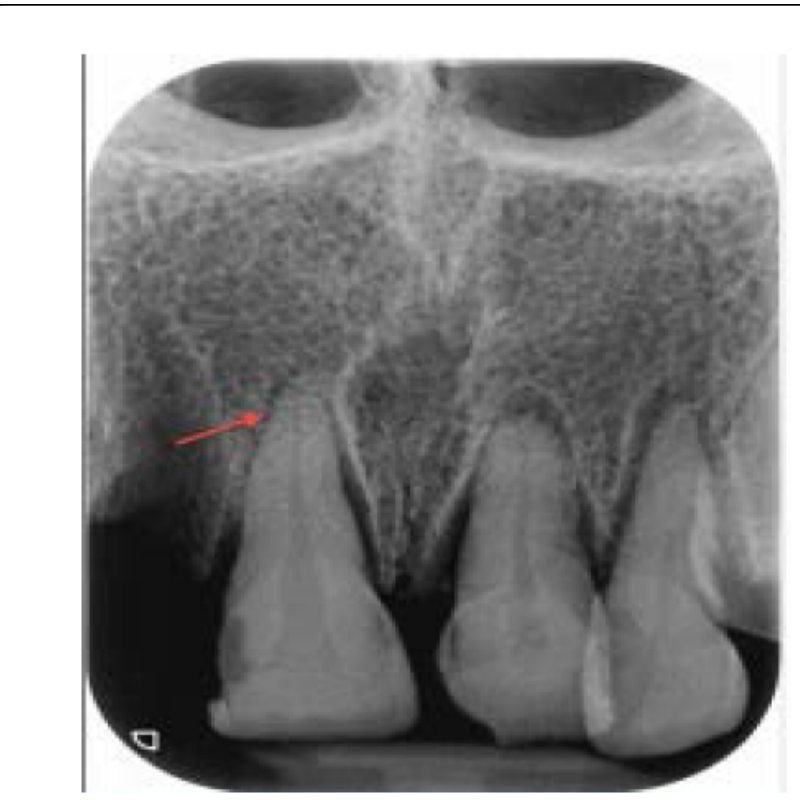

Figure 4: Detection of HRF in periapical image.

Intraoral radiography is a major help in detection of root fractures. We should look for a radiolucent line between the fragments and discontinuity of periodontal ligament at the site [3,25-27]. However small sedentary root fractures particularly before soft tissue proliferation between the fragments might be not seen in periapical radiographs [28]. For simulating clinical condition we fractured the tooth roots in a horizontal plane accurately and then glued the fragment together tightly in their first locations.

The fracture line is more oblique in cervical region than middle and apical regions of root and the fracture line will be seen only when the central X ray beam expose it within the maximum range if 15 to 20 degrees. So a single periapical radiograph cannot detect fractures and it should be provided at least in 3 different angles $\left(45^{\circ}, 90^{\circ}\right.$ and $\left.110^{\circ}\right)$ in one of them X-ray be parallel with fracture line to view the fracture $[17,28]$.

Many dentists replaced conventional intraoral films with digital systems because of lower radiation dose, faster imaging time and better patient education $(29,30)$.

Diagnosis of this type of fracture is considered as a challenge for all dentists.

New guidelines suggest the CBCT technique to detect HRFs in addition to periapical radiographs [22].

Superimposition of dental and root structures are the limitation in periapical radiographs as the first Para clinical findings. Recently, CBCT has overcome the limitations of periapical radiography $[22,23]$.

Intraoral radiography, provides a two-dimensional image, while in the case of CBCT, multi planar information from the axial, coronal, and cross sectional dimensions allows the diagnosis of fractures which are routinely missed in two-dimensional radiographs [3].

The diagnostic accuracy of CBCT images can be affected by scatter and beam hardening artifacts which are caused by presence of high- density structures like enamel, metallic posts, amalgam and root canal fillings [31].

Costa FF, et al. [12] showed that metallic posts in the root canals decrease the diagnostic accuracy of HRFs in CBCT (Figure 5). So we did not use the metallic posts to avoid the artifacts which caused by these objects.

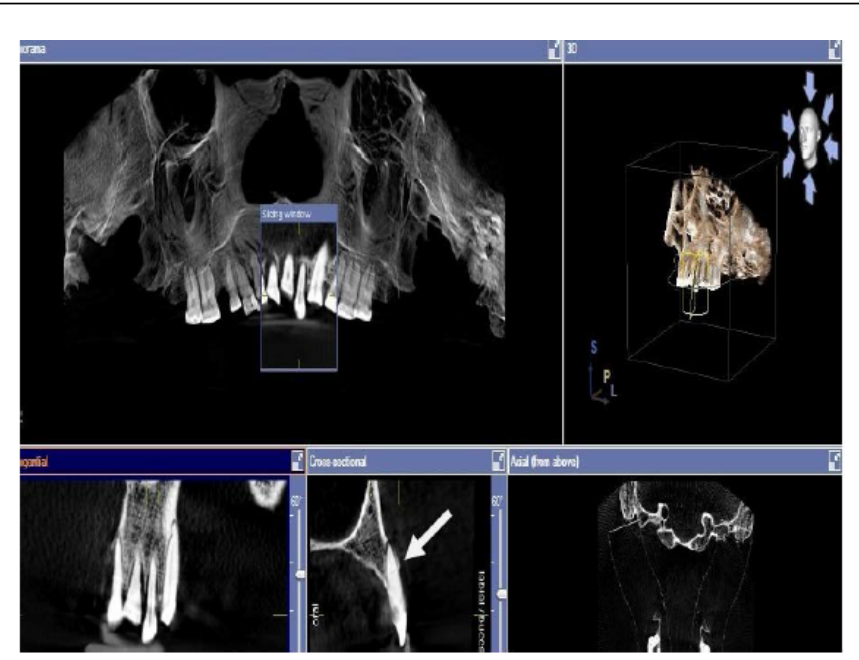

Figure 5: Detection of HRF in CBCT images.

Likublo, et al. [32] compared the accuracy of multi-detector CT and CBCT in detection of dog's anterior teeth HRFs and stated that CBCT is the most reliable imaging modality for detection of these fractures.

High X -ray dose, high cost of taking pictures, and the need for skills and training in reading images are disadvantages of CBCT. So it is necessary to know the indications of this technique. [33-35].

In this study, the sensitivity and accuracy of CBCT and periapical methods were compared. The sensitivity and specificity of CBCT radiography was 0.97 and 0.93 , and periapical was 0.83 and 0.885 respectively, indicating that the $\mathrm{CBCT}$ technique was preferred to the periapical to detect the horizontal fracture of the root.

Bornstein, et al. [26] compared a conventional radiography and restricted FOV CBCT to detect the presence of HRFs of permanent teeth and their location in the root. In this study, 38 patients with the age of 8 to 52 years (average of 24 years old) were studied. This study totally had 44 teeth with horizontal fracture; intraoral radiography was done including periapical and occulusal as well as CBCT technique with restricted FOV.

Diagnosis of fracture site showed significant difference between periapical radiography and CBCT in $30 \%$ of cases. On the other hand, since determining the location of the fracture is important for prognosis, the use of CBCT is recommended. This finding is consistent with our research.

Wang, et al. [36] concluded that the CBCT technique had more accuracy and reliability than the intraoral technique for detection of root fractures, which is consistent with the results of this study.

Avsever, et al. [28] collected 82 anterior maxillary teeth that did not have any horizontal fracture. They fractured 31 teeth and 31 teeth were considered as control group. They mounted them randomly in dried skull in upper maxillary bone. Different radiographic images including 
Citation: Hashemnia SM, Jahadi S, Shaygannia S, Hekmatian E, Habibollahi A, et al. (2018) Cone Beam Computed Tomography and Digital Periapical Radiography in Determining Horizontal Root Fractures: An In-vitro Comparative Study. Dentistry 8: 513. doi: $10.4172 / 2161-1122.1000513$

Page 5 of 6

a 3D Accuatomo 170 CBCT, a New Tom 3G CBCT, Vista Scan PSP , a CCD Sensor and a Conventional film from each teeth were done. The sensitivity and specificity of these radiographic methods were calculated. The final results showed that 3D Accuatomo 170 CBCT has the highest sensitivity and diagnostic power for horizontally root fractures and СВCT should be considered as the images that have the highest acceptability for root fractures diagnosis. These findings are similar to our results.

Brady, et al. [37] stated that periapical radiography and CBCT are unreliable in detecting partial fractures. In fact, complete fractures can be detected more easily in different radiographs. In our study, fractures were complete and this could change the CBCT results.

Talayi pour, et al. [38] selected 60 teeth including 24 anterior teeth and 36 multi-root posterior mandibular teeth. Randomly 15 teeth were fractured horizontally. 15 teeth were fractured vertically with hammer (the rest of the teeth were considered as control group), fractured segments were connected and were mounted in a dry sheep mandible. Digital periapical images and CBCT were done. Results showed that CBCT images have higher sensitivity and higher specificity than digital periapical for diagnosis of horizontal and vertical root fracture that is consistent with results of this study.

Kamburoglu, et al. [3] assembled 50 extracted lateral and central incisors without any fracture, anomalies, pathologic lesions and root erosion. In 18 teeth a horizontal fracture was made by mechanical force by a hammer, the fragments were glued together. At 3 different angles $\left(45^{\circ}, 90^{\circ}, 135^{\circ}\right)$, the periapical images were taken. CCD, CBCT and RVG images were taken too. The images were studied by 3 observers and the results were analyzed. It was reported that CBCT images significantly had a higher sensitivity compared to the PA, RVG and CCD systems. However, no statistical difference was seen between the four systems, which did not fit with our study in the case of specificity.

Kobayashi-Velasco, et al. [39] mounted 60 dog's anterior teeth (40 fractured and 20 intact teeth) in 60 dog's maxilla (40 with alveolar fracture and 20 intact bones) then digital periapical radiographs were taken with two different vertical projections followed by CBCT images with small field of view. There was no significant difference between sensitivity and specificity of these two techniques for detection of root fractures that contradicts our findings this might be due to including all types of root fractures (vertical and horizontal) not only horizontal ones.

We used a medical LCD monitor (LG, Seoul, Korea) $(6900 \times 1440$ pixels, 32 bits) for viewing the images which has a higher contrast ratio, spatial resolution and maximum luminance than usual computer monitors. Some researchers reported higher accuracy for medical monitors in detection of caries compared to routine computer monitors [40-43], but there is no study about comparing medical and computer monitors in detection of HRFs.

Barayan, et al. [44] concluded that there is no significant difference between digitally enhanced and non-enhanced periapical images in detection of HRFs. Additionally they reported that there is no significant difference between endodontists and oral radiologists in detection of such fractures.

The observers (an endodontist and an oral radiologist) were free to use any enhancement tools in our study.

Based on the studies, the effective dose of CBCT depends on exposure parameters, area under examination and volumes size of exposure and is within the range of 11 to 77 microSiverts and it is lower in anterior maxilla than other sites [45].

The effective dose for conventional intraoral images is 10 to 83 and for panoramic is $4-30$ microSiverts [46] so although CBCT is an accurate imaging modality for detection of root fractures but based on ALARA (as low as reasonably achievable) it must be used only for symptomatic patients that periapical images did not show any fractures $[3,39]$.

\section{Suggestions and Limitations}

As the $\mathrm{CBCT}$ technique has a high radiation dose, region of interest (ROI) should be restricted to a single tooth to reduce the dose.

It was difficult for us to find central and lateral incisors free of any fractures, root caries and root erosion.

This is an in vitro study so we could not assess the indirect evidences of root fracture like bony lesions in crest of alveol, perilateral radiolucencies and halo lesion in periodontal structures.

\section{Conclusion}

Despite the results of this study which was along with many previous studies, attention to the limitations of the CBCT technique, including higher radiation dose and insufficient accessibility compared to intra-oral radiography, makes prescribing this imaging modality more doubtful. When a mid-root fracture is seen in the primary periapical radiograph Cone-beam technique is recommended to detect the fracture pattern. When there are signs of fracture and it is not seen in periapical radiograph, CBCT should be considered or otherwise periapical radiographs from two different angles must be done. Periapical images with a $90^{\circ}$ angle according to root axis detect HRFs in the cervical and apical region more efficiently, and in the middle region 45-degree images have the highest sensitivity to detect the horizontal root fracture.

\section{References}

1. Grimm S, Frazão P, Antunes JLF, Castellanos RA, Narvai PC (2004) Dental injury among Brazilian schoolchildren in the state of São Paulo. Endod Dent Traumatol 20: 134-138.

2. Calişkan M, Pehlivan Y (1996) Prognosis of root-fractured permanent incisors. Endod Dent Traumatol 12: 129-136.

3. Kamburoğlu K, Ilker Cebeci A, Gröndahl HG (2009) Effectiveness of limited cone-beam computed tomography in the detection of horizontal root fracture. Dent Traumatol 25: 256-261.

4. Hovland EJ (1992) Horizontal root fractures: Treatment and repair. Dent Clin North Am 36: 509-525.

5. Poi WR, Manfrin TM, Holland R, Sonoda CK (2002) Repair characteristics of horizontal root fracture: a case report. Dent Traumatol 18: 98-102.

6. Cvek M (1992) Prognosis of luxated non-vital maxillary incisors treated with calcium hydroxide and filled with gutta-percha. A retrospective clinical study. Dent Traumatol 8: 45-55.

7. Andreason J, Ship AG (1982) Traumatic injuries of the teeth. Plast Reconstr Surg 70: 771.

8. Orhan K, Aksoy U, Kalender A (2010) Cone-beam computed tomographic evaluation of spontaneously healed root fracture. J endod 36: $1584-1587$.

9. De Vos W, Casselman J, Swennen GR (2009) Cone-beam computerized tomography (CBCT) imaging of the oral and maxillofacial region: a 
Citation: Hashemnia SM, Jahadi S, Shaygannia S, Hekmatian E, Habibollahi A, et al. (2018) Cone Beam Computed Tomography and Digital Periapical Radiography in Determining Horizontal Root Fractures: An In-vitro Comparative Study. Dentistry 8: 513. doi: 10.4172/2161-1122.1000513

Page 6 of 6

systematic review of the literature. Int J Oral and Maxillofac Surg 38: 609-625.

10. Lofthag-Hansen S (2010) Cone beam computed tomography radiation dose and image quality assessments. Swed Dental J Suppl 209: 4-55.

11. Mehralizade S, Nemati Anaraki S, Sakhdari S, Miraba S, Amiri Siavashani $\mathrm{M}$, et al. (2016) Comparing the diagnostic accuracy of two different resolutions of radiographs captured with PSP digital intraoral receptors in detection of secondary caries.

12. Costa FF, Gaia BF, Umetsubo OS, Cavalcanti MGP (2011) Detection of horizontal root fracture with small-volume cone-beam computed tomography in the presence and absence of intracanal metallic post. J endod 37: 1456-1459.

13. Andreasen FM, Andreasen JO, Bayer T (1989) Prognosis of rootfractured permanent incisors- prediction of healing modalities. Dent Traumatol 5: 11-22.

14. Cavalcanti MG (2012) Cone beam computed tomographic imaging. J Craniofac Surg 23: 279-282.

15. Andreasen FM, Andreasen JO (1988) Resorption and mineralization processes following root fracture of permanent incisors. Dent Traumatol 4: 202-214.

16. Pindborg J (1955) Clinical, radiographic, and histological aspects of intraalveolar fractures of upper central incisors. Acta Odontol Scand 13: 41-67.

17. Cohen S, Burns RC (1998) Pathways of the pulp: Mosby St. Louis.

18. Bornstein MM, Wölner-Hanssen AB, Sendi P, Von Arx T (2009) Comparison of intraoral radiography and limited cone beam computed tomography for the assessment of root-fractured permanent teeth. Dent Traumatol 25: 571-577.

19. Andreasen JO, Ahrensburg SS, Tsilingaridis G (2012) Root fractures: the influence of type of healing and location of fracture on tooth survival rates-an analysis of 492 cases. Dent Traumatol 28: 404-409.

20. Clark SJ, Eleazer P (2000) Management of a horizontal root fracture after previous root canal therapy. Oral Surg Oral Med Oral Pathol Oral Radiol Endod 89: 220-223.

21. Kositbowornchai S, Sikram S, Nuansakul R, Thinkhamrop B (2003) Root fracture detection on digital images: effect of the zoom function. Dent Traumatol 19: 154-159.

22. Durack C, Patel S (2012) Cone beam computed tomography in endodontics. Braz Dent J 23: 179-191.

23. Patel S, Dawood A, Whaites E, Pitt Ford T (2009) New dimensions in endodontic imaging: part 1. Conventional and alternative radiographic systems. Int Endod J 42: 447-462.

24. Winzap-Kälin C, Hänni S (2005) Injuries to permanent teeth. Part 1: diagnosis of the tooth injury. Schweizer Monatsschrift fur Zahnmedizin= Revue mensuelle suisse d'odonto-stomatologie Rivista mensile svizzera di odontologia e stomatologia 115: 133-143.

25. Borelli P, Alibrandi P (1999) Unusual horizontal and vertical root fractures of maxillary molars: an 11-year follow-up. J Endod 25: 136-139.

26. Bornstein MM, Wolner-Hanssen AB, Sendi P, von Arx T (2009) Comparison of intraoral radiography and limited cone beam computed tomography for the assessment of root-fractured permanent teeth. Dent Traumatol 25: 571-577.

27. Wenzel A, Kirkevang LL (2005) High resolution charge-coupled device sensor vs. medium resolution photostimulable phosphor plate digital receptors for detection of root fractures in vitro. Dent Traumatol 21: 32-36.

28. Avsever H, Gunduz K, Orhan K, Uzun İ, Ozmen B, et al. (2013) Comparison of intraoral radiography and cone-beam computed tomography for the detection of horizontal root fractures: an invitro study. Clin oral investig 18: 285-292.
29. Scarfe WC, Farman AG (2008) What is cone-beam CT and how does it work? Dent Clin North Am 52: 707-730.

30. Scarfe WC, Farman AG, Sukovic P (2006) Clinical applications of conebeam computed tomography in dental practice. J Can Dent Assoc 72: 75.

31. Kamburoğlu K, Murat S, Yüksel SP, Cebeci ARİ, Horasan S (2010) Detection of vertical root fracture using cone-beam computerized tomography: an in vitro assessment. Oral Surg Oral Med Oral Pathol Oral Radiol Endod 109: e74-e81.

32. Likubo M, Kobayashi K, Mishima A, Shimoda S, Daimaruya T, et al (2009) Accuracy of intraoral radiography, multidetector helical CT, and limited cone-beam CT for the detection of horizontal tooth root fracture. Oral Surg Oral Med Oral Pathol Oral Radiol Endod 108: e70-e74.

33. Affairs ADACoS (2012) The use of cone-beam computed tomography in dentistry: an advisory statement from the American Dental Association Council on Scientific Affairs. J Am Dent Assoc 143: 899-902.

34. Hatcher DC (2010) Operational principles for cone-beam computed tomography. J Am Dent Assoc 141: 3S-6S.

35. Scarfe WC (2011) "All that glitters is not gold": standards for cone-beam computerized tomographic imaging. Oral Surg Oral Med Oral Pathol Oral Radiol Endod 111: 402-408.

36. Wang P, Yan X, Lui D, Zhang W, Zhang Y et al. (2011) Detection of dental root fractures by using cone-beam computed tomography. Dentomaxillofac Radiol 40: 290-298.

37. Brady E, Mannocci F, Brown J, Wilson R, Patel S (2013) A comparison of cone beam computed tomography and periapical radiography for the detection of vertical root fractures in nonendodontically treated teeth. Int Endod J 47: 735-746.

38. Talayi Pour A, Hafezi L, Yarahmadi A, Ghaznavi A, Iranparvar A, et al. Comparison of the diagnostic accuracy of digital intraoral radiography with PSP and CBCT in detection of horizontal and vertical dental root fractures. J Res Dentomaxillofac Sci 1: 32-38.

39. Kobayashi-Velasco S, Salineiro FCS, Gialain IO, Cavalcanti MGP (2017) Diagnosis of alveolar and root fractures: an in vitro study comparing CBCT imaging with periapical radiographs. J Appl Oral Sci 25: 227-233.

40. Al-Ekrish Aaa, Ekram MI, Al Faleh W, Alkhader M, Al-Sadhan Re (2012) The validity of different display monitors in the assessment of dental implant site dimensions in cone beam computed tomography images. Acta Odontol Scand 71: 1085-1091.

41. Hellen-Halme K, Petersson A, Warfvinge G, Nilsson M (2008) Effect of ambient light and monitor brightness and contrast settings on the detection of approximal caries in digital radiographs: an in vitro study. Dentomaxillofac radiol 37: 380-384.

42. İlgüy $M$, Dinçer S, İlgüy D, Bayirli G (2008) Detection of artificial occlusal caries in a phosphor imaging plate system with two types of LCD monitors versus three different films. J digit imaging 22: 242-249.

43. Kutcher MJ, Kalathingal S, Ludlow JB, Abreu M, Platin E (2006) The effect of lighting conditions on caries interpretation with a laptop computer in a clinical setting. Oral Surg Oral Med Oral Pathol Oral Radiol Endod 102: 537-543.

44. Barayan M, Nasseh I, Geha H, Noujeim M (2017) The Effects of Imaging Enhancement Tools in the Detection of Horizontal Root Fractures. Journal of clinical and diagnostic research: JCDR 11: Zc98-zc101.

45. Lofthag-Hansen S, Thilander-Klang A, Ekestubbe A, Helmrot E, Grondahl K (2008) Calculating effective dose on a cone beam computed tomography device: 3D Accuitomo and 3D Accuitomo FPD. Dentomaxillofac radiol 37: 72-79.

46. Haiter-Neto F, Wenzel A, Gotfredsen E (2008) Diagnostic accuracy of cone beam computed tomography scans compared with intraoral image modalities for detection of caries lesions. Dentomaxillofac radiol 37: $18-22$. 